\title{
MAPA DO CARSTE DA REGIÃO DE PEDRO LEOPOLDO - LAGOA SANTA, MINAS GERAIS, BRASIL - 1:50.000
}

Jean-Pierre COUTARD

Heinz Charles KOHLER

André JOURNAUX

\begin{abstract}
RESUMO
Republicação do "Mapa do Carste da Região de Pedro Leopoldo - Lagoa Santa, Minas Gerais, Brasil - 1:50.000" e comentário, originalmente publicado pelo Laboratório de Análise e de Cartografia de Formações Superficiais da Universidade de Caen e Centro de Geomorfologia do CNRS em Caen, em junho de 1978. Pesquisa desenvolvida no âmbito do convênio entre o Laboratório de Pedologia e Sedimentologia do Instituto de Geografia / Departamento de Geografia da Faculdade de Filosofia, Letras e Ciências Humanas da Universidade de São Paulo e o Centre de Géomorphologie du CNRS - Caen, sob a coordenação de J.P. Queiroz Neto e A. Journaux. Em Minas Gerais, a coordenação dos trabalhos coube a H.C. Kohler, A. Prous e G. Vargas Barbosa (UFMG).
\end{abstract}

Palavras-chave: Cartografia geomorfológica; Relevo cárstico; Formações superficiais; Geomorfologia do Quaternário; Paleoambiente.

\section{RÉSUMÉE}

CARTE DU KARST DE LA REGION DE PEDRO LEOPOLDO - LAGOA SANTA, MINAS GERAIS, BRASIL - 1:50.000. Réédition de la "Carte du Karst de la Region de Pedro Leopoldo - Lagoa Santa, Minas Gerais, Brasil - 1:50.000" et du commentaire, initialement publié par le Laboratoire d'Analyse et de Cartographie des Formations Superficielles de l'Université de Caen, et le Centre de Géomorphologie du Centre National de la Recherche Scientifique à Caen, en 1978. Recherches développés dans le cadre de l' accord entre le Laboratoire de Pédologie et Sédimentologie de l'Institut de Géographie / Département de Géographie de FFLCH de l'Université de São Paulo et du Centre de Géomorphologie du CNRS - Caen, sous la coordination de J.P. Queiroz Neto et A. Journaux. A Minas Gerais la coordination a ete apporté par H.C. Kohler, A. Prous et G. Vargas Barbosa (UFMG).

Mots clés: Cartographie géomorphologique; Relief karstique; Formations superficielles; Géomorphologie Quaternaire; Paléoenvironnement.

\section{ABSTRACT}

MAP OF THE KARST OF THE PEDRO LEOPOLDO - LAGOA SANTA REGION, MINAS GERAIS, BRASIL - 1:50,000. Republication of the "Map of the Karst of the Pedro Leopoldo - Lagoa Santa Region, Minas Gerais, Brasil - 1:50,000" and explanatory memorial, originally published by the Laboratoire d'Analyse et de Cartographie des Formations Superficielles de l'Université de Caen, and the Centre de Géomorphologie - CNRS - Caen, in 1978. Research developed under the agreement between the Laboratory of Pedology and Sedimentology of the Institute of Geography / Department of Geography of FFLCH from the University of São Paulo and the Geomorphology Center of the CNRS in Caen, under the coordination of J.P. Queiroz Neto and A. Journaux. In Minas Gerais, the activities were coordinated by H.C. Kohler, A. Prous and G. Vargas Barbosa (UFMG).

Keywords: Geomorphological cartography; Karst landform; Surficial formations; Quaternary geomorphology; Paleoenvironment. 


\section{INTRODUÇÃO}

A região cartografada situa-se entre 20 e 30 $\mathrm{km}$ ao norte de Belo Horizonte (Minas Gerais) e se inscreve num retângulo de $15 \mathrm{~km}$ por $20 \mathrm{~km}$, englobando os municípios de Lagoa Santa, Pedro Leopoldo e Matosinhos.

Os planaltos, cujas altitudes variam entre 600 e 900 m, são intensamente carstificados. São constituídos pelas rochas do Grupo Bambuí (base do Supergrupo São Francisco), que recobrem o escudo gnáissico, datando do fim do Pré-Cambriano $600 \pm 50 \mathrm{Ma}$. e compostas, na zona estudada, por calcários, calco-xistos e filitos, injetadas de numerosos filões de quartzo. O calcário é geralmente puro, pouco poroso, maciço com uma fácies coraliana, oolítico ou localmente marmório. A base do Supergrupo São Francisco é formada pelo conglomerado da Formação Carrancas.

O Grupo Bambuí é moderamente plissado, na maioria das vezes simplesmente ondulado, mas bastante fraturado por falhas e diáclases orientadas no sentido NE-SW e NW-SE, orientações existentes igualmente nas unidades geológicas que circundam a bacia do São Francisco. É fraturado também por diáclases oblíquas de forte inclinação da ordem de $30^{\circ}$ a $45^{\circ}$ (Varginha, Baú). Estas fraturas se formaram ou foram reativadas durante os últimos episódios do ciclo brasileiro 570-620 Ma.

\section{HIDROLOGIA DO CARSTE}

Dois domínios se opõem nitidamente sobre a carta. Ao norte e oeste de Lagoa Santa e ao sul de Matosinhos, os filitos alterados cobertos pelo cerrado ocupam vastas superfícies. A drenagem superficial é densa, o escoamento difuso e concentrado é intenso, e as voçorocas (ravinas) são numerosas, bem como os fundos de vales úmidos. Em torno de Pedro Leopoldo, Matosinhos e Fidalgo, ao contrário, o calcário está presente em toda parte, o escoamento superficial é muito local - as valas e regos evoluem a sumidouros - e o essencial da drenagem é subterrâneo. Somente o vale do Samambaia é uma exceção. Uma floresta seca e uma vegetação xerófila povoam os afloramentos calcários, enquanto determinados fundos de depressão são ocupados por florestas de tipo mais úmido.

As numerosas informações recolhidas durante o levantamento da carta, mostram que o escoamento geral das águas do carste é diretamente dependente da inclinação geral das camadas, di- rigida para leste, localmente para nordeste ou sudeste, e também da disposição da rede de fraturas. A inclinação das camadas é mais forte $\left(12^{\circ}\right.$ a $\left.15^{\circ}\right)$ e mais irregular nas proximidades do ribeirão da Mata, mais fraca $\left(4^{\circ}\right.$ a $\left.6^{\circ}\right)$ e mais regular em direção ao rio das Velhas.

Sobre a carta aparecem com clareza as principais redes de escoamento. As águas do Palmeira e das depressões de Matosinhos se dirigem para Poções, e depois para o Mucambo, afluente do rio das Velhas. Note-se que neste setor a circulação das águas é semiaérea e semissubterrânea. As águas do Confins e do Carroção vêm para Lapa Vermelha antes de se unirem ao Samambaia. Este rio é alimentado por importantes ressurgências, das quais uma possui depósitos de tufo. $\mathrm{O}$ Sumidouro do Fidalgo, bem alimentado pela bacia cárstica do Samambaia, perde suas águas pelos sumidouros de seu paredão oriental; a principal ressurgência se situa em Olho d'Água, na margem direita do rio das Velhas. As águas da zona de Cerca Grande vão se unir ao Mucambo. O conjunto do sistema cárstico estudado se liga consequentemente ao rio das Velhas e é independente do ribeirão da Mata.

O carste da região de Lagoa Santa caracteriza-se pela abundância de dolinas coalescentes que continuam a se aprofundar. Os lagos temporários de limites variáveis são muito numerosos e a grande diversidade de altitudes de seus fundos dá uma ideia da complexidade das circulações subterrâneas. Sobre a carta foram estabelecidos os limites de extensão máxima dos lagos (conhecidos através de cartas antigas e de fotografias aéreas, de levantamentos de campo, estudo da extensão de depósitos lacustres silto-argilosos, da extensão de solos hidromórficos ou a concreções de ferro e manganês), e os limites dos lagos em novembro de 1977, após um período de seca normal. Em 1976, depois de um período de seca excepcional, o próprio Sumidouro de Fidalgo estava quase seco, percorrido somente pelos meandros dos braços do Samambaia. Os níveis máximos e mínimos dos lagos têm uma periodicidade da ordem de 15 anos. Certos lagos quando chegam ao seu nível máximo, apresentam uma lamina d'água que pode ultrapassar $15 \mathrm{~m}$ no ponto mais profundo (Confins, Lapa Vermelha); por vezes galerias abandonadas e suspensas acima dos sumidouros atuais funcionam temporariamente (Poções). Infelizmente as informações espeleológicas são ainda muito escassas para que se possa ter um bom conhecimento da zona de oscilação do lençol d'água. Só a cir- 
culação "vadose" foi objeto de algumas verificações. O escoamento subterrâneo é permanente em Palmeira, Poções e Lapa Vermelha.

As numerosas flutuações do nível da água dos lagos cársticos, se opõem à relativa estabilidade dos lagos pseudocársticos instalados sobre os filitos: Lagoa dos Mares, Lagoa Santa.

As águas de superfície não são duras: grau de dureza alemão inferior a 5, e ligeiramente ácidas: pH 6,5 (medidas efetuadas em Lagoa Funda, Confins e Rio das Velhas). As águas do carste têm uma dureza média: grau de dureza alemão, 9 , seu pH é nitidamente básico: 7,5 a 8 (medidas efetuadas em Lapa Vermelha, Poções e sobre as ressurgências do Samambaia). Após as chuvas abundantes da estação úmida, as águas superficiais se carregam de areias e de argilas tomando uma coloração avermelhada, ao contrário dos cursos d'água fortemente influenciados pelo carste, que permanecem claros (Samambaia, Jaque inferior).

\section{EVOLUÇÃO DO CARSTE}

O carste apresenta-se ainda parcialmente recoberto por um material complexo proveniente do depósito de antigas superfícies e a alteração in loco dos filitos ricos em filões de quartzo e do calcário (orela chocolate de descarbonização, em geral no contato com a rocha). Todo este material foi mais ou menos remanejado por processos de coluvionamento e obtura as lápias e as diáclases oblíquas e verticais.

A evolução do carste e seu aprofundamento podem ser constatados graças ao encaixamento das dolinas, particularmente nítidos em Macaco, Cerca Grande, Varginha, e à superposição das grutas, abrigos e aberturas sobre os grandes paredões calcários. Uma boa concordância existe frequentemente entre os testemunhos de antigos fundos de depressões e a posição das aberturas sobre os paredões. As medidas feitas mostram que em todos os grandes conjuntos, um nível de antigos sumidouros se verifica de 30 a $35 \mathrm{~m}$ acima dos atuais. Este nível pode ser relacionado com o ciclo médio do Rio das Velhas quando houve o estabelecimento de terraços a 20 e $25 \mathrm{~m}$ acima do curso atual. Um segundo nível de antigos sumidouros situa-se entre 12 e $15 \mathrm{~m}$ acima do nível atual do escape das águas. Os mais belos exemplos de superposição de sumidouros são visíveis em Lapa Vermelha, Macaco-Baú, Faustina (Matosinhos) e Cerca Grande.
As depressões estão em vias de aprofundamento: pequenas dolinas e sumidouros funcionais.

\section{AS FORMAS CÁRSTICAS}

Entre as formas subterrâneas é preciso citar as grutas e as galerias. Todas têm uma ligação estreita com as diáclases principais da rocha, pois as diáclases de descompressão paralelas aos paredões são raras (Cerca Grande, Lapa Mortuária). A maior parte das grutas é de pequena dimensão, não obstante algumas apresentarem dimensões não negligenciáveis. Por exemplo Lapa Vermelha I mede $30 \mathrm{~m}$ de largura e 15 a $20 \mathrm{~m}$ de altura; Ballet, $20 \mathrm{~m}$ de comprimento por $8 \mathrm{~m}$ de altura; a maior gruta de Cerca Grande atinge 40 metros de largura e $40 \mathrm{~m}$ de comprimento, com uma altura média de $7 \mathrm{~m}$; em Poções, um antigo curso de rio subterrâneo pode ser percorrido numa extensão de 350 m; e em Lapinha a gruta aberta ao público pode ser visitada numa extensão que varia de 150 a 200 $\mathrm{m}$ de comprimento, com $40 \mathrm{~m}$ de desnivelamento.

Muitas grutas são de fato seções de galerias paragenéticas, muito altas e estreitas (Lapa Vermelha III e VI, Baú, Poções, Caieiras), possuindo bancos laterais alongados e vestígios de $p i$ sos estalagmíticos suspensos, indicando o limite de antigos processos de colmatagem e de antigos níveis de escoamento. Da mesma forma, os restos de brechas situam-se próximos aos tetos (Lapinha, Lapa Vermelha). Belos meandros de abóbada e pináculos inversos são visíveis em Lapa Vermelha e Baú. A extremidade dos pingentes de abóbada frequentemente se descolaram, dependendo do tipo de junção de estratificação, provavelmente no momento do esvaziamento das galerias (desabamento de vazante).

Antigas galerias singenéticas (em direção forçada) de seção elíptica e sem colmatagem existem em Cerca Grande.

Os pisos estalagmíticos raramente se conservaram (destruídos pelas escavações arqueológicas), mas os travertinos e as barragens estalagmíticas podem ser vistas em Lapinha e Poções. Em virtude do caráter maciço e pouco poroso do calcário, as estalactites estão estreitamente localizadas sobre as fraturas; os tetos permanecem lisos.

As formas superficiais são de três tipos: formas côncavas do tipo dolina, lápias, e formas lineares do tipo paredão. As dolinas de desmoronamento com paredão vertical ou em poços, são as menores e as mais raras (planalto de Lapa Vermelha, Carroção). A maior parte tem uma for- 
ma geral de funil ou de bacia, e uma dessimetria pronunciada com oposição de um paredão calcário e de uma vertente recoberta de coluviões sobre os quais escorrem as águas de chuva. As dolinas alinham-se sobre as principais fraturas (um belo exemplo pode ser encontrado entre Cocho d'Água e Fidalgo) e as depressões mais extensas situam-se sobre os cruzamentos das diáclases maiores: Macaco, Varginha.

Uma só grande depressão merece o nome de planície cárstica: a de Mocambeiro ocupada por numerosos lagos mais ou menos temporários e com limites variáveis: Lagoa Redonda, Lagoa Maria Angélica, Boca de Sumidouro e Vargem da Pedra. A planície está cercada de relevos: maciço de Macaco e maciço de Cerca Grande a leste e sudeste, maciço de Poções a oeste, maciço da Fazenda Jaguara a noroeste (fora da carta). Edificada em função do nível de base do rio das Velhas e de seu afluente, o Mocambo, esta planície possui vários humes perto de Mocambeiro (Vargem da Pedra) e da Fazenda Experiência. O pequeno maciço de Caetano é um hume em vias de desembaraçar-se dos materiais que o circundam.

Um vale "aveugle" (vale cego) de pequena dimensão localiza-se a noroeste de Lapinha. O vale mais representativo deste tipo é o de Palmeira; as formas "reculées" e gargantas são raras.

Entre as formas decimétricas, convém citar as microlápias que modelam certas superfícies, mas sobretudo cinzelam os paredões nas entradas dos sumidouros em virtude de sua carga em ácidos húmicos e em fragmentos vegetais em vias de decomposição. Assim também as lápias horizontais se desenvolvem na porção superficial do carste, onde a atividade biológica é intensa, e colocam em valor as juntas de estratificação. Finalmente, citamos as grandes caneluras estreitas que ranhuram os paredões verticais.

A uma fase de biostasia sob cobertura vegetal densa, favorável a uma intensa alteração dos calcários e de calco-xistos com formação de bolsões e de grandes lápias mais ou menos numerosas, segundo a densidade da diáclase, sucedeu-se uma fase de resistasia, de um lado antrópica, que provocou uma ablação irregular do manto de alteritas. Quando a denudação da cobertura é parcial, somente afloram os cimos de esporões rochosos; é o caso da vertente com verrugas. Se a desobstrução é mais completa podemos constatar o aparecimento de torres, cujas larguras podem atingir vários metros, algumas vezes mais de um decâmetro, e com altura que varia de 5 a 15 m (Samambaia,
Varginha, Baú). Outras vezes grandes corredores são totalmente desobstruídos, verdadeiras ruelas dividem os maciços calcários (Lapinha, Cerca Grande, Carroção, Periperi). O conjunto MacacoBaú, reveste-se de um aspecto ruiniforme com seus pilares, torres, arcos e galerias.

Mais que os maciços calcários que aparecem amplamente desembaraçados das alteritas e dos coluviões, como os de Cerca Grande e Lapinha, os grandes paredões são o traço característico da região cárstica estudada. Estes paredões atingem frequentemente de 45 a $60 \mathrm{~m}$ de altura (Lapa Vermelha, Macaco-Baú, Poções, Cerca Grande); os maiores correspondem a acidentes tectônicos importantes, via preferencial do escoamento das águas, e apresentam gargantas formadas por desmoronamento, em sua base: Terraço, Varginha, Periperi. O mais belo conjunto se desenvolve de Cocho d’Água a Confins. É preciso notar também o aspecto quadrangular da depressão de Varginha, orientada pelas fraturas. A evolução dos paredões inicia-se a partir de um escavamento em sua base e por desmoronamentos. Alguns desses desmoronamentos estão ligados à presença de diáclases oblíquas alargadas pelo fenômeno da dissolução.

Quase todos os paredões apresentam uma obliquidade que permite o estabelecimento de abrigos pouco profundos e de grandes alturas. A. Journaux explica a origem destas formas da seguinte maneira: no início, a combinação da inclinação das camadas e da posição das diáclases maiores orienta o escoamento das águas e da origem ao nascimento de sumidouros por onde as águas desaparecem. Um pequeno paredão se forma, então, desprovido de uma cobertura suscetível de manter a umidade, assegurando a dissolução do calcário; ele se imuniza enquanto que a alteração prossegue no resto da depressão. Todavia, a dissolução continua ativa na base do paredão, onde as águas superficiais desaparecem, e onde as águas dos lagos temporários se estagnam. A combinação do aprofundamento vertical e do recuo lateral explica assim a forma inclinada dos paredões. Não obstante, os maiores "encorbellements" estão ligados a desmoronamentos orientados pelas diáclases oblíquas: Poções (Lapa do Chapéu), Varginha, Sumidouro, ou então, estão orientados pela abertura de antigas galerias. Os entalhes secundários estão ligados aos antigos níveis de água existentes quando as dolinas estavam menos escavadas. 


\section{PREENCHIMENTO DAS GRUTAS E DOS ABRIGOS - A OCUPAÇÃO HUMANA}

Quase todas as acumulações de depósitos nas grutas e abrigos foram alteradas pelas escavações arqueológicas do século XIX e início do atual. Salvo raras exceções, tornou-se impossível empreender-se um estudo estratigráfico. Somente o grande abrigo de Lapa Vermelha IV (P.L.) foi objeto de um estudo detalhado. A acumulação atinge aí uma espessura de $15 \mathrm{~m}$. As datações vão de $25.000 \mathrm{BP}$ a 1.620 BP. O material concentra-se atrás de blocos provenientes de um desabamento antigo do paredão. As lentes alongadas de areia e silte, nas quais se intercalam níveis argilosos, testemunham uma sedimentação levada a cabo por águas calmas, na entrada de um sumidouro.

O estudo detalhado do local (A.J. 1975-1977) evidenciou as oscilações antigas do nível do lago temporário da dolina, cujo fundo está hoje a cerca de $50 \mathrm{~m}$ abaixo do abrigo, e sobretudo mostrou certas flutuações do clima no Quaternário recente; após o período de escavamento da dolina, um depósito argiloso se acumula entre 25.000 e 10.000 BP; em seguida intervém um período seco que se prolonga de 10.000 a $6.000 \mathrm{BP}$ com sedimentos carbonatados e depósitos estalagmíticos; segue-se um período mais úmido -6.000 a $3.000 \mathrm{BP}$ com um nível do lago elevado e com sedimentos dispostos em pequenas camadas, sedimentos de sumidouros, descarbonatados. Finalmente instala-se um período mais seco, de 3.000 a nossos dias, com sedimentos carbonatados pulverulentos. Em Cerca Grande, C. de Paula Couto identificou um clima seco entre 11.000 e $8.000 \mathrm{BP}$ e outro mais úmido entre 8.000 e 4.000 BP.

Uma fauna Quaternária importante foi encontrada nos depósitos dos abrigos e das grutas. Compreende os Desdentados (Megatérios, Glossotérios, Tatus, Gliptidontes); os Artiodáctilos (Camelídeos, Suídeos, Cervídeos, Equídeos, Tapirídeos); os Proboscídeos (Mastodontes); os Carnívoros (Machairodus, Felídeos, Canídeos, Ursídeos); os Marsupiais e os Roedores. Em Lapa
Vermelha (P.L.) a fauna da base (25.000 - 10.000 $\mathrm{BP})$ é constituída por roedores, cervídeos e suídeos de tamanho médio, enquanto a fauna do topo é de tamanho menor: roedores, lagartos e restos de peixes.

A presença do homem se traduz pela descoberta de esqueletos, instrumentos, cerâmica e pinturas rupestres. Os principais sítios que forneceram vestígios humanos são: Sumidouro: 30 esqueletos, Eucalipto: 14 sepulturas, Lapa Mortuária de Confins: 80 indivíduos. O mobiliário pertence às civilizações pré-cerâmicas que ocuparam as grutas e abrigos, e às civilizações cerâmicas que, ou asseguraram a continuidade da ocupação nestes mesmos lugares, ou criaram novos sítios a céu aberto (Poções, Vargem da Pedra, Lapa Vermelha, Arruda). Os instrumentos podem ser de três tipos: o primeiro constituído por "chopping-tools" e facas, trabalhados em seixos de quartzo e de jaspe. $\mathrm{O}$ segundo, em pedra lascada, como facas, escavadeiras e pontas de flecha em quartzo. E, finalmente, machados e discos em pedra polida. Três sítios forneceram datações anteriores a 9.000 anos BP para as camadas de ocupação humana: Caieiras, Cerca Grande e Lapa Vermelha (P.L.).

Com exceção da gruta de Ballet, todas as pinturas estão localizadas sobre os paredões de abrigos e recebem o sol no meio do dia (das 12 às 14 horas). Os mais belos conjuntos são os de Sumidouro: bastões, signos rabiscados, cervídeos; os de Cerca Grande: cervídeos, crocodilos, tatus, macacos, peixes, pássaros; e de Ballet: pinturas antropomórficas, peixes, cervídeos. As pinturas de Lapa Vermelha são anteriores a 3.800 BP.

As pinturas rupestres estão hoje ameaçadas pelas calcitas que se depositam por escoamento sobre os paredões, pela lavagem e pelos depósitos de ferro e calcita, ligados às cheias dos lagos (Cerca Grande), pela descamação local da rocha e pelas inscrições de turistas (graffitis). É lícito pensar que se tratava de acampamentos temporários, onde pescadores e caçadores faziam pequenas moradias, não construídas, protegidas pelos abrigos sob rochas.

\section{Autores consultados:}

M. Coutinho Beltrão, F.F.M. de Almeida, E.O. Ferreira (Carta tectônica do Brasil), A. Journaux, H.C. Kohler, A. Laming-Emperaire, J. Nicod, A. Prous, Ph. Renault, W.U. Schoell, A.W. Romano e M. Teixeira da Costa (Mapa Geológico do Estado De Minas Gerais), J. Tricart. 
Créditos:

Redação do memorial explicativo:

Jean-Pierre Coutard e André Journaux (Centre de Géomorphologie du CNRS); Heinz Charles Kohler (Laboratório de Pedologia e Sedimentologia - Inst. Geog. - USP e Instituto de Geociências - Departamento de Geografia - UFMG - Belo Horizonte).

Levantamento e elaboração da carta:

H.C. Kohler, A.M. Cançado, D.G. Gomes, F.L. Macieira, N.R. Nascimento (Departamento de Geografia - UFMG - Belo Horizonte); A. Journaux, J.P. Coutard, D. Alduc, J. Pellerin (Centro de Geomorfologia do CNRS e Universidade de Caen); A. Laming-Emperaire e A. Prous (Missão Franco-Brasileira de Arqueologia e Setor de Arqueologia - UFMG - Belo Horizonte); J.P. de Queiroz Neto, L. Coltrinari, R.P. Dias Ferreira, S.M. Stanowski (Laboratório de Sedimentologia e Pedologia - IGEOG-USP, São Paulo).

Desenho definitivo:

Michele Lavollé, Centro de Geomorfologia do CNRS em Caen.

Pesquisas financiadas pelos seguintes organismos:

UFMG - Belo Horizonte, Instituto de Geociências, Depto. de Geografia; CNPq UFMG, Belo Horizonte; Centro de Geomorfologia do CNRS - Caen; FAPESP, São Paulo; CNPq, Rio de Janeiro.

Impressão e publicação:

Laboratório de Análise e de Cartografia de Formações Superficiais da Universidade de Caen e Centro de Geomorfologia do CNRS - Caen.

Tradução em português:

Luzia Mesquita de Almeida Simons e Maria Regina Sader. 